\title{
Near-Roof Air Temperatures: Modelling the Implications for HVAC Performance and Cool Roofs
}

\author{
Alan Green ${ }^{1}$, Laia Ledo Gomis ${ }^{1}$, Riccardo Paolini², Shamila Haddad², Georgios Kokogiannakis ${ }^{1}$, \\ Paul Cooper ${ }^{1}$, Zhenjun $\mathrm{Ma}^{1}$, Buyung Kosasih ${ }^{1}$, Mattheos Santamouris ${ }^{2}$ \\ ${ }^{1}$ Sustainable Buildings Research Centre, University of Wollongong, Wollongong, Australia \\ ${ }^{2}$ Faculty of the Built Environment, University of New South Wales, Sydney, Australia
}

\begin{abstract}
Conventionally in building performance simulations (BPS), it is assumed that air entering outdoor HVAC equipment is at the outdoor 'ambient' temperature, obtained from a weather file. However, significant spatial variations exist in outdoor air temperature fields, especially within the thermal boundary layers that form near exposed surfaces like roofs.

Experiments were conducted at three large-footprint shopping centre buildings, to characterise the above-roof temperature field. An empirical model was derived from the experimental data, and applied in BPS of a shopping centre with rooftop HVAC equipment in seven Australian climates. In these cases, the electricity savings and gas 'penalties' attributable to cool roofs would have been underestimated by $44-85 \%$ (61\% on average) if near-roof air temperature variations had not been modelled accurately.
\end{abstract}

\section{Introduction}

Cool roofs are known to reduce the energy consumption of conditioned buildings during hot periods (e.g. see reviews by Santamouris, et al. (2011); EPA (2014); Pisello (2017)). The high solar reflectance and high thermal emittance of such roof materials are known to minimise the roof surface temperature elevation above ambient temperature, thereby reducing heat transfer through the roof structure. Many previous studies have modelled these effects in building performance simulations (BPS), by accounting for cool roof solar reflectance and thermal emittance in the roof-surface energy balance. However, several industry and scientific publications have claimed that the benefits of cool roofs are underestimated by conventional BPS practices, since the local air temperatures surrounding rooftop HVAC equipment are not taken into account (Wray and Akbari, 2008; Carter, 2011; Pisello et al., 2013; Carter and Kosasih, 2015). The relatively low surface temperature of cool roofs produces above-roof air temperature fields colder than those that form above conventional 'non-cool' roofs. Such reductions in near-roof air temperature could significantly affect building energy consumption, by reducing the inlet temperature of rooftop ventilation systems and the 'on-coil' air temperature of rooftop heat exchangers.

This paper outlines the development and application of an empirical model that accounts for the effects of near-roof air temperature fields in BPS of large-footprint buildings, such as shopping centres and airport terminals. It is likely that near-roof air temperature fields have an especially large effect on the performance of HVAC systems installed on such buildings, since the large roof surface areas could allow thermal boundary layers to become well established, and HVAC equipment is often installed on the roof. Similar effects could also apply to buildings with smaller roofs; however, they were not included in the scope of the present work. The remainder of this paper has been organised into three primary sections, respectively describing: i) the experiments used to develop the aboveroof temperature model, ii) the model itself, and iii) a BPS study of a large-footprint shopping-centre building in seven Australian climates, in which the effects of the model were investigated.

\section{Experiments}

\section{Test Buildings}

Experiments were conducted during the summer of 2017/18 and autumn of 2018, at three shopping centre buildings within $150 \mathrm{~km}$ of Sydney, Australia (Figure 1). The buildings occupied footprints (i.e. plan areas) in the range 16,000-76,000 $\mathrm{m}^{2}$, and varied in height between 5 $\mathrm{m}$ and $20 \mathrm{~m}$. Other buildings nearby were not significantly taller than the test buildings, such that they would be likely to have a large effect on wind flow around the buildings of interest.

All three buildings had low-angled roofs comprised of metal-coated and/or painted steel sheets, with solar reflectance in the range $0.26-0.61$ and thermal emittance in the range $0.42-0.85$ (solar reflectance and thermal emittance were measured according to ASTM E 1918 (ASTM, 2016) and ASTM C 1371 (ASTM, 2015), respectively). Two of the three buildings also had concrete rooftop car parking facilities, and all three buildings had HVAC units and arrays of photovoltaic panels installed on the roof.

\section{Method}

At each building, roof surface temperatures, near-roof air temperatures and local meteorological conditions were monitored for periods in excess of six weeks. Fifteen short masts were installed on each roof, each fitted with four Hobo TMCX-HD thermistors (accuracy of $\pm 0.1^{\circ} \mathrm{C}$ ), which were shielded from direct and reflected solar radiation and installed such that they measured the roof 
surface temperature and air temperatures at heights of $0.15,0.5$ and $1.5 \mathrm{~m}$ above the roofs (Figure 2).

A Gill MetPak Pro weather station, fitted a Middleton Solar EQ08-SE pyranometer, a Middleton Solar PG01-E pyrgeometer and a RIMCO-7499-STD tipping-bucket rain gauge, was also installed above each roof during their respective monitoring periods. The weather station monitored air temperature $\left( \pm 0.1^{\circ} \mathrm{C}\right)$, humidity $( \pm 0.8 \%$ relative humidity at $23^{\circ} \mathrm{C}$ ), horizontal wind velocity $( \pm 2 \%$ of reading at $\left.12 \mathrm{~m} \mathrm{~s}^{-1}\right)$, barometric pressure $( \pm 50 \mathrm{~Pa})$, net hemispherical short-wave irradiance (with accuracy exceeding that required of Secondary Standard pyranometers in ISO 9060), net hemispherical long-wave irradiance and rainfall. All weather station measurements except rainfall were taken at the top of an $8 \mathrm{~m}$-tall mast, near the centre of each roof (Figure 1).
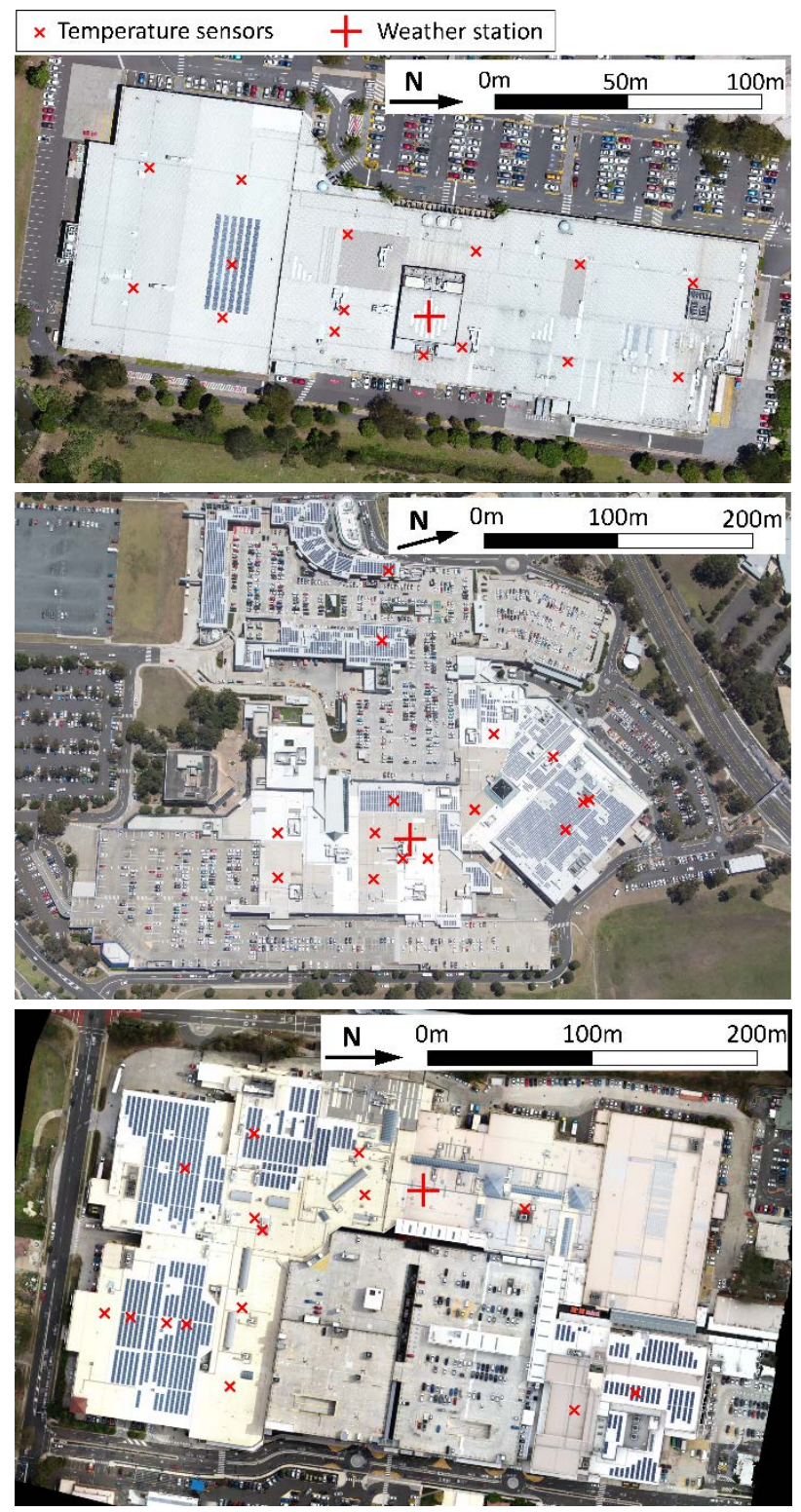

Figure 1: Aerial photographs of the three test buildings, with the location of test equipment marked in red.

\section{Above-Roof Temperature Model}

\section{Model Development}

The empirical 'above-roof temperature model' was developed based on data from the experiments described above. A combined dataset was formed, including temperature measurements from the three buildings that were collected in unobstructed regions of the roofs (i.e. not within arrays of photovoltaic panels or immediately adjacent to rooftop HVAC equipment), together with the corresponding meteorological measurements.

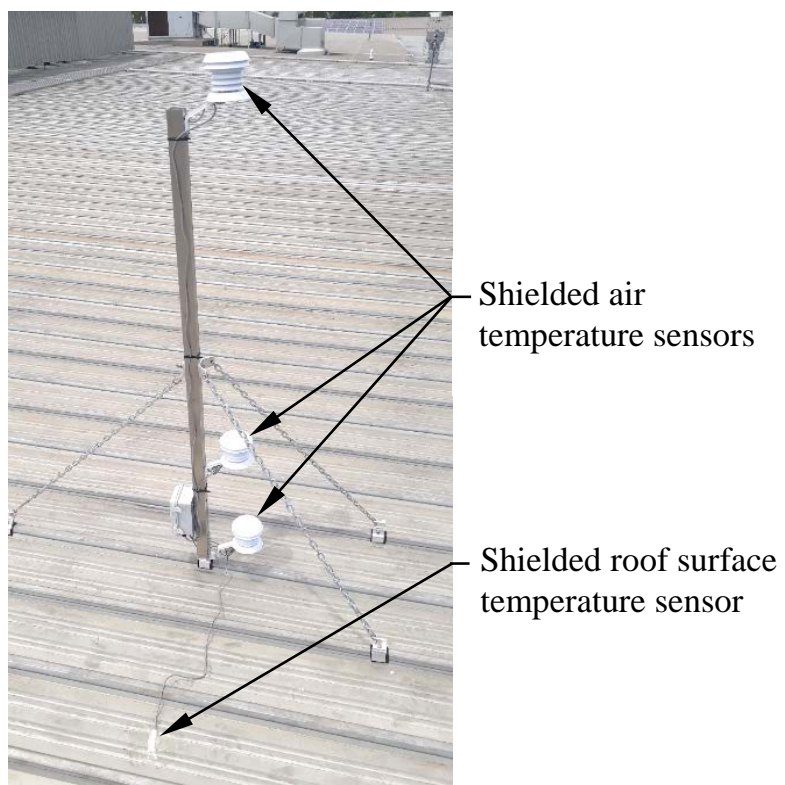

Figure 2: One of the fifteen short masts, fitted with four temperature sensors, that were installed on the roofs.

A normalised temperature, $T^{*}$, was defined such that, within the thermal boundary layer, it would vary from 1 at the roof surface to 0 at the height above the roof that the 'ambient' temperature had been measured, $z_{\text {ref }}(8 \mathrm{~m}$ in the present study). $T^{*}$ was defined as:

$$
T^{*} \equiv \frac{T-T_{r e f}}{T_{S}-T_{\text {ref }}}
$$

where $T$ is the local air temperature, $T_{S}$ is the spatially averaged roof surface temperature and $T_{\text {ref }}$ is the air temperature at height $z_{\text {ref }}$.

A logarithmic mean temperature profile, analogous to the logarithmic mean velocity profile often used to describe the atmospheric boundary layer (Richards and Norris, 2011), was defined and used to approximate the aboveroof thermal boundary layer. The normalised temperature at a height $z$ above the roof surface was given by:

$$
T^{*}=1-\left(\frac{\ln \left(\frac{z+10^{\alpha}}{10^{\alpha}}\right)}{\ln \left(\frac{z_{r e f^{+10^{\alpha}}}}{10^{\alpha}}\right)}\right)
$$

where the parameter $\alpha$ is used to set the shape of the profile, as shown in Figure 3. 


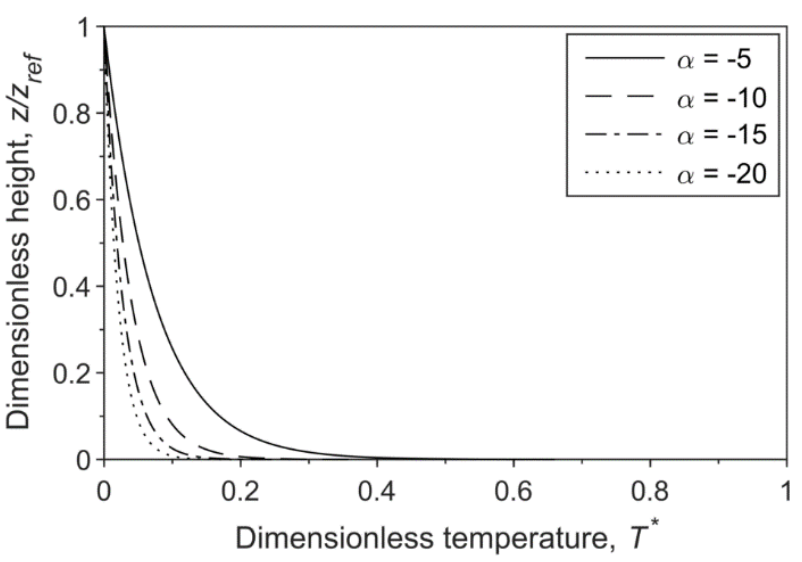

Figure 3: The vertical air temperature profile used to approximate the mean above-roof temperature field in

the present study, plotted for several values of $\alpha$.

It should be noted that in non-neutral boundary layer flows (i.e. those in which buoyant forces are significant), wall-normal temperature profiles are typically not exactly logarithmic (Monin and Obukhov, 1954). Moreover, the boundary-layer flow above roofs is likely to be disturbed significantly by flow separation at the roof leading edge and by rooftop obstructions to the flow (e.g. HVAC equipment), so above-roof temperature fields are unlikely to match a theoretical boundary layer profile exactly, even when buoyancy is not significant. The logarithmic profile was adopted in the present work in order to provide an approximation of reality, which would improve the current assumptions in building simulations, without introducing excessive complexity to the above-roof temperature model.

The vertical temperature profile (Equation 2) was fitted individually to each measurement within the combined experimental dataset, using an iterative least-squares method. The logarithmic profile fitted the majority of measured values very well, with $53 \%$ of the coefficients of determination $\left(\mathrm{R}^{2}\right)$ above 0.9 (Figure 4 ). Thus, the shape (or depth) of the measured thermal boundary layer at each point in time and space was characterised by a fitted $\alpha$ value.

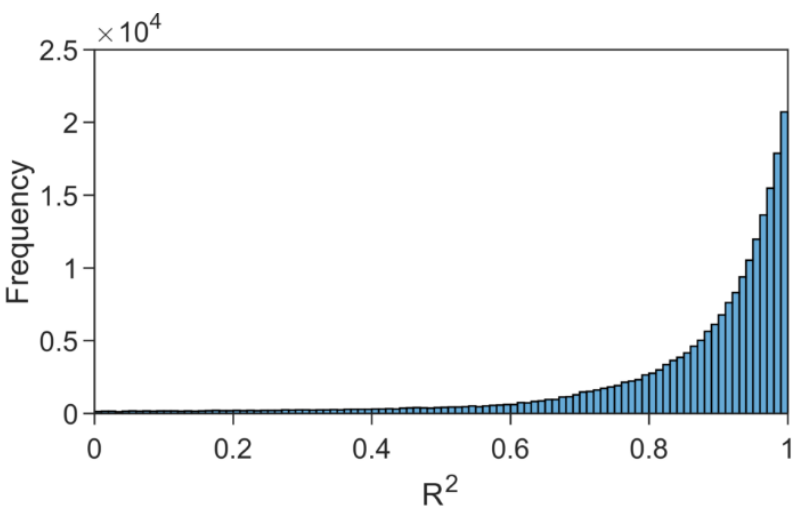

Figure 4: Goodness of fit (expressed in terms of the coefficient of determination; $R^{2}$ ) obtained fitting logarithmic profiles to each vertical set of temperature measurements in the combined experimental dataset.

Analysis of the fitted $\alpha$ values and corresponding meteorological conditions revealed correlations between $\alpha$, the wind speed measured by the weather station, $u_{r e f}$, and the temperature difference $d T=\left(T_{s}-T_{\text {ref }}\right)$. In stable conditions (i.e. when $d T<0$ ), $\alpha$ could be predicted with relatively high accuracy using the Richardson number (Figure 5), which represents the ratio of buoyant forces to inertial forces within the air flow above the roof:

$$
R i=\frac{g \beta\left(T_{s}-T_{r e f}\right) L}{u_{r e f}^{2}},
$$

Here, $g \approx 9.81 \mathrm{~m} \mathrm{~s}^{-2}$ is the acceleration due to gravity, $\beta \approx 1 / T_{\text {ref }}$ is the thermal expansion coefficient of air ( $T_{\text {ref }}$ must be expressed in Kelvin), $L \equiv \sqrt{A}$ is the characteristic length scale of the roof, $A$ is the roof surface area, and $u_{\text {ref }}$ is the reference wind speed. The relevance of $R i$, and shape of the correlation depicted in Figure 5a, can be explained by the influence of $u_{r e f}$ and $d T$ on the convection of heat above the roof surface. In stable conditions, buoyant forces dampen the vertical mixing of heat but inertial forces (exerted by wind) tend to enhance it, so the ratio of these forces is a good indicator of the depth of the thermal boundary layer that will form.
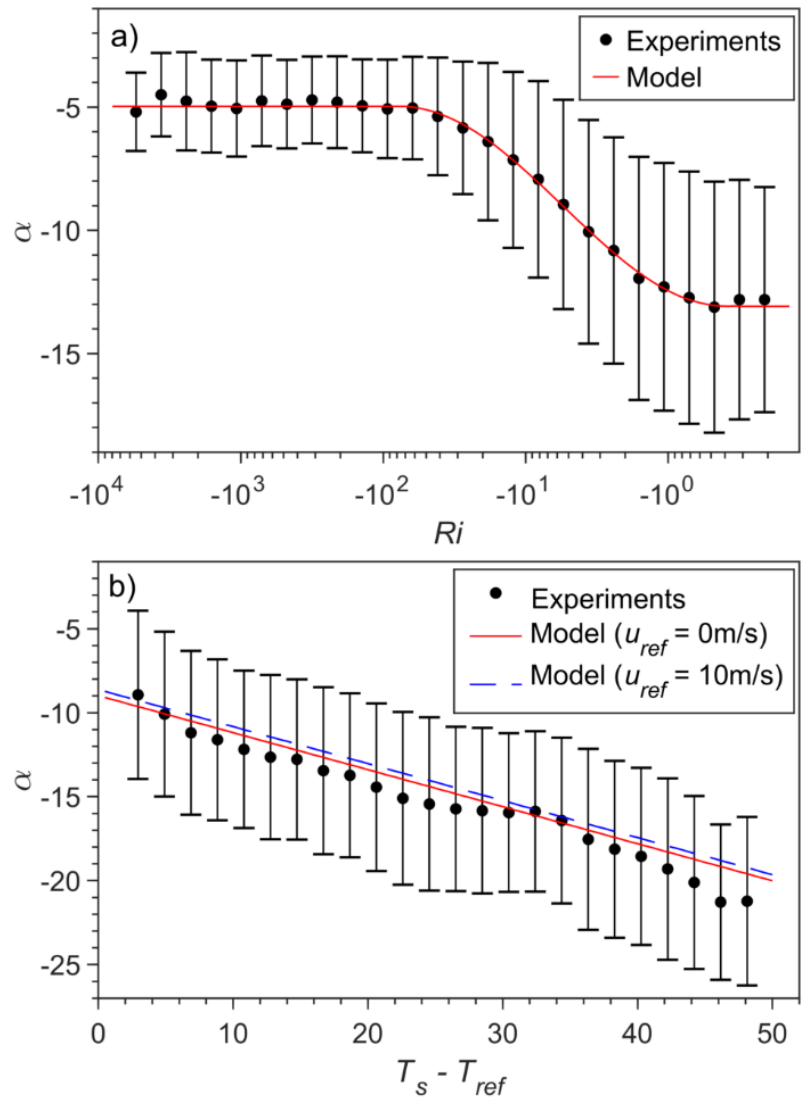

Figure 5: Comparison of the thermal boundary layer shape parameter, $\alpha$, obtained from experimental data with those predicted by the above-roof temperature model, in a) stable and b) unstable conditions.

Experimental data has been represented by the mean (dot) and standard deviation (whiskers) of $\alpha$ within discrete bins.

In unstable conditions (i.e. when $d T>0$ ), buoyant forces enhance the vertical mixing of heat, while wind could either enhance convection, or suppress it by disrupting buoyancy-driven vertical mixing. The $\alpha$ values obtained 
from experimental data tended to decrease with increasing $d T$ (Figure 5b), indicating stronger vertical mixing of heat and a thinner thermal boundary layer. The wind speed, $u_{\text {ref }}$, appeared to have relatively little effect on the thermal boundary layer in these conditions. A relatively accurate predictive model was formed for $\alpha$ in unstable conditions by fitting a planar surface to the experimental data within the $d T$, $u_{\text {ref }}$ space.

Many factors that affect above-roof temperature fields were not taken into account in this simplified model, e.g. spatial variations in roof surface temperature, horizontal variations in the temperature field due to air flow patterns, and atmospheric stability in the region surrounding the building. Consequently, a significant amount of variance in the experimental data was not explained by the model, as is evident in Figure 5. Nevertheless, implementation of the above-roof temperature model in building simulations is a vast improvement on not taking such near-field temperatures into account at all. Use of the model to predict the measured near-roof air temperatures, rather than assuming they equal $T_{r e f}$, reduced the RMS error from $1.73 \mathrm{~K}$ to $0.52 \mathrm{~K}$, reduced the mean error in stable conditions from $1.11 \mathrm{~K}$ to $0.12 \mathrm{~K}$, and reduced the mean absolute error in unstable conditions from $1.63 \mathrm{~K}$ to 0.05 K. Furthermore, the simplicity of the model allows a relatively small set of input variables to be used, all of which are readily available in BPS.

\section{Model Definition}

Within BPS, the mean air temperature entering rooftop HVAC equipment, $T_{H V A C}$, can be estimated at each timestep using Equations 3-6. Once the mean roof surface temperature, $T_{s}$, has been calculated at each time step, Equations 3-4 provide a means to establish $\alpha$. If it is then assumed that air is drawn-in evenly from the range of heights spanned by the HVAC inlet duct-from $z_{1}$ (measured from the roof surface to the base of the duct) to $z_{2}$ (measured from the roof surface to the top of the duct) - the mean inlet temperature is given by Equation 5 . Equation 6 is an integrated form of Equation 5, which could be more convenient for use in BPS software.

\section{Model Implementation in BPS}

In the present study, the above-roof temperature model was implemented in EnergyPlus, utilising the energy management system (EMS) which allows customised modelling routines and controls to be implemented at the time-step level (NREL, 2015). The input parameters $L, z_{1}$ and $z_{2}$ depend on the position and dimensions of the HVAC inlet ducts, and they were therefore set as (userdefined) constants prior to the simulation. At each timestep, the EMS script extracted the input variables for the ambient weather, $T_{\infty}$ and $u_{r e f}$, from the weather file, read $T_{s}$ from the output of the simulation run at the future predicted time step, and set the air temperature at the HVAC air loop inlet to the calculated value $T_{H V A C}$ using Equations 3, 4 and 6 (Figure 6).

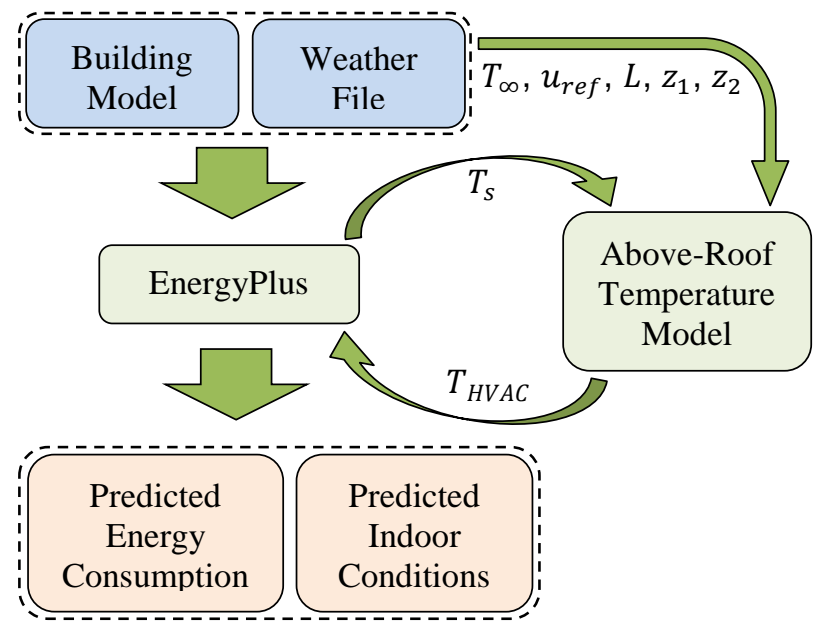

Figure 6: Schematic diagram showing how the aboveroof temperature model was implemented in a building performance simulation.

$$
\begin{gathered}
\alpha=\left\{\begin{array}{cc}
-8.983+0.03607 u_{\text {ref }}-0.2205\left(T_{s}-T_{\text {ref }}\right) & R i \geq 0 \\
-13.08 & -10^{-0.51} \leq R i<0 \\
-9.025+4.055 \sin \left(\frac{\pi}{2}\left(\log _{10}(-R i)-0.64\right)\right) & -10^{1.79} \leq R i<-10^{-0.51} \\
-4.97 & R i<-10^{1.79}
\end{array}\right. \\
T_{H V A C}=\frac{1}{z_{2}-z_{1}} \int_{z_{1}}^{z_{2}}\left(T_{S}-\left(T_{S}-T_{r e f}\right) \frac{\ln \left(\frac{z+10^{\alpha}}{10^{\alpha}}\right)}{\ln \left(\frac{8+10^{\alpha}}{10^{\alpha}}\right)}\right) d z \\
T_{H V A C}=T_{S}-\frac{\left(T_{S}-T_{r e f}\right)}{\left(z_{2}-z_{1}\right) \ln \left(\frac{8+10^{\alpha}}{10^{\alpha}}\right)}\left[\left(z_{2}+10^{\alpha}\right) \ln \left(\frac{z_{2}+10^{\alpha}}{10^{\alpha}}\right)-z_{2}+z_{1}-\left(z_{1}+10^{\alpha}\right) \ln \left(\frac{z_{1}+10^{\alpha}}{10^{\alpha}}\right)\right]
\end{gathered}
$$

\section{Building Performance Simulations}

A set of 56 simulations were conducted, to test the effects of the above-roof temperature model on simulations of large-footprint buildings. The simulations were run using EnergyPlus v8.9 and the simulation manager jEPlus v.1.7.2 (Zhang, 2011). The convective heat transfer coefficient algorithm developed by (Clear et al., 2003) was used for the roof external surface, since it was based on experimental data from the flat roofs of commercial buildings, and was one of the few algorithms available that took roof size into account (EnergyPlus, 2010; Mirsadeghi et al., 2013; Costanzo et al., 2014).

\section{Building Model}

A building model was developed, to represent a shopping centre with a rectangular $350 \mathrm{~m} \times 200 \mathrm{~m}$ roof and a height of $13.5 \mathrm{~m}$. It was modelled with a concrete slab 
foundation, concrete walls, steel sheet roof and windowto-wall ratio of $5 \%$. Three indoor zones were defined in the building model, one in each of two storeys, and one representing an unconditioned ceiling space. Insulation in the building ceiling and walls was set according to the minimum requirements of the Australian National Construction Code of 2016 (NCC2016) (Australian Building Codes Board, 2016); these requirements varied according to the climate zone, e.g. the roof R-value varied from 3.2 to $3.7 \mathrm{~m}^{2} \mathrm{~K} \mathrm{~W}^{-1}$ in the cases investigated.

Simulations were run with roof radiative properties representing: i) a new metal-coated (e.g. zinc-aluminium coated) steel roof with solar reflectance of 0.67 and thermal emittance of 0.3 , and ii) a new cool roof with solar reflectance of 0.77 and thermal emittance of 0.87 .

\section{HVAC Systems}

The indoor air temperature in each of the two occupied zones was maintained in the range $22-24.5^{\circ} \mathrm{C}$ by separate variable-air-volume HVAC systems, which were designed according to ASHRAE Standard 90.1-2010 Appendix G (ASHRAE, 2010). Separate simulations were run with air-cooled condenser coils and wet cooling towers, to compare the effect of augmented near-roof air temperatures on each type of system. Heating was provided by gas-fired boilers in a hot water loop.

Each HVAC component was sized automatically such that the indoor temperature set-point was always met, and the nominal cooling and heating capacities of the HVAC systems were, respectively, 1.15 and 1.25 times the peak capacities required to do so. It was assumed that the aircooled condensers, wet cooling towers and ventilation air inlets were located on the building roof, with inlet ducts spanning the height range from $z_{1}=0.5 \mathrm{~m}$ to $z_{2}=2 \mathrm{~m}$.

\section{Weather}

International Weather for Energy Calculations (IWEC) climate files were used to simulate typical weather conditions for seven Australian cities, each representing one of the Australian climate zones defined in NCC2016 (Table 1); RMY files were used for zones 3 and 4, since no IWEC files were available. The files had been developed in compliance with requirements outlined in the Building Code of Australia (EnergyPlus ${ }^{\mathrm{TM}}$, 2006).

Table 1: Climate zones simulated and the city from which weather data was used.

\begin{tabular}{|c|c|c|}
\hline Zone & Description & City \\
\hline 1 & $\begin{array}{c}\text { High humidity summer, warm } \\
\text { winter }\end{array}$ & Darwin \\
\hline 2 & $\begin{array}{c}\text { Warm humid summer, mild } \\
\text { winter }\end{array}$ & Brisbane \\
\hline 3 & Hot dry summer, warm winter & Alice Springs \\
\hline 4 & Hot dry summer, cool winter & Dubbo \\
\hline 5 & Warm temperate & Sydney \\
\hline 6 & Mild temperate & Melbourne \\
\hline 7 & Cool temperate & Canberra \\
\hline
\end{tabular}

\section{Loads and Schedules}

Thermal loads and schedules associated with the building operation were set according to NCC2016, where possible
(Table 2). The equipment load was increased above the NCC2016 value of $5 \mathrm{~W} \mathrm{~m}^{-2}$, to $10 \mathrm{~W} \mathrm{~m}^{-2}$, to account for loads that are common in shopping centres but not within the typical retail shop, e.g. vending machines, cooking equipment in food courts, and any refrigeration in supermarkets that is not conditioned by rooftop units.

Table 2: Internal loads and schedules used in the BPS.

\begin{tabular}{|c|c|}
\hline Parameter & Setting \\
\hline Lighting load & $22 \mathrm{~W} \mathrm{~m}^{-2}$ \\
\hline Equipment load & $10 \mathrm{~W} \mathrm{~m}^{-2}$ \\
\hline Maximum occupant density & $3 \mathrm{~m}^{2}$ person $^{-1}$ \\
\hline Occupant sensible load & $75 \mathrm{~W}$ person $^{-1}$ \\
\hline Occupant latent load & $55 \mathrm{~W}$ person $^{-1}$ \\
\hline Lighting schedule & $\begin{array}{c}100 \% \text { from } 7: 00 \text { and } 19: 00, \\
10 \% \text { otherwise }\end{array}$ \\
\hline Equipment schedule & $\begin{array}{c}\text { 70\% from 7:00 and 19:00, } \\
10 \% \text { otherwise }\end{array}$ \\
\hline Occupancy schedule & $\begin{array}{l}\text { Varies, maximum of } 25 \% \\
\text { reached during 11:00-13:00 }\end{array}$ \\
\hline HVAC schedule & On between 7:00 and 18:00 \\
\hline $\begin{array}{c}\text { Infiltration rate (at natural } \\
\text { pressure) }\end{array}$ & 0.7 air changes per hour \\
\hline Ventilation rate & $10 \mathrm{~L} \mathrm{~s}^{-1}$ person $^{-1}$ \\
\hline
\end{tabular}

\section{Results and Discussion}

Implementation of the above-roof temperature model increased the simulated annual electricity consumption of the building HVAC system by $2.5-13.2 \%$ (6.62\% on average), and decreased the simulated annual gas consumption by $6.6-12.2 \%$ (8.16\% on average), when the metal-coated roof was simulated (Figure 7). This consistent increase in electricity consumption and decrease in gas consumption can be understood by considering that the building was only conditioned between 7:00 and 18:00, so the roof is likely to have been hot most of the time that the HVAC system operated, generating an above-roof air temperature field warmer than 'ambient'. Thus, the above-roof temperature model typically: i) reduced the efficiency of rooftop heat exchangers and increased the thermal load associated with ventilation during periods in which cooling was required, and ii) decreased the thermal load associated with ventilation when heating was required.

When simulations of buildings with and without cool roofs were compared, the above-roof temperature model had a much more pronounced effect. Cool roofs remained much closer to the 'ambient' temperature during the day, which mitigated the above-roof temperature effects on HVAC performance significantly. Figure 8 presents the annual electricity savings and gas 'penalty' (i.e. extra gas consumption) attributable to the use of a cool roof rather than a metal-coated steel roof, calculated for the building with air-cooled condensers. In these cases, the above-roof temperature model increased the estimated electricity savings by $77-555 \%$ ( $219 \%$ on average), and increased the gas penalty by $137-178 \%$ (153\% on average). The model affected simulations involving water-cooled condensers by a similar magnitude; however, when expressed as a percentage, the effect on electricity savings was typically much higher in those cases. 
$\square$ Without model $\square$ With model
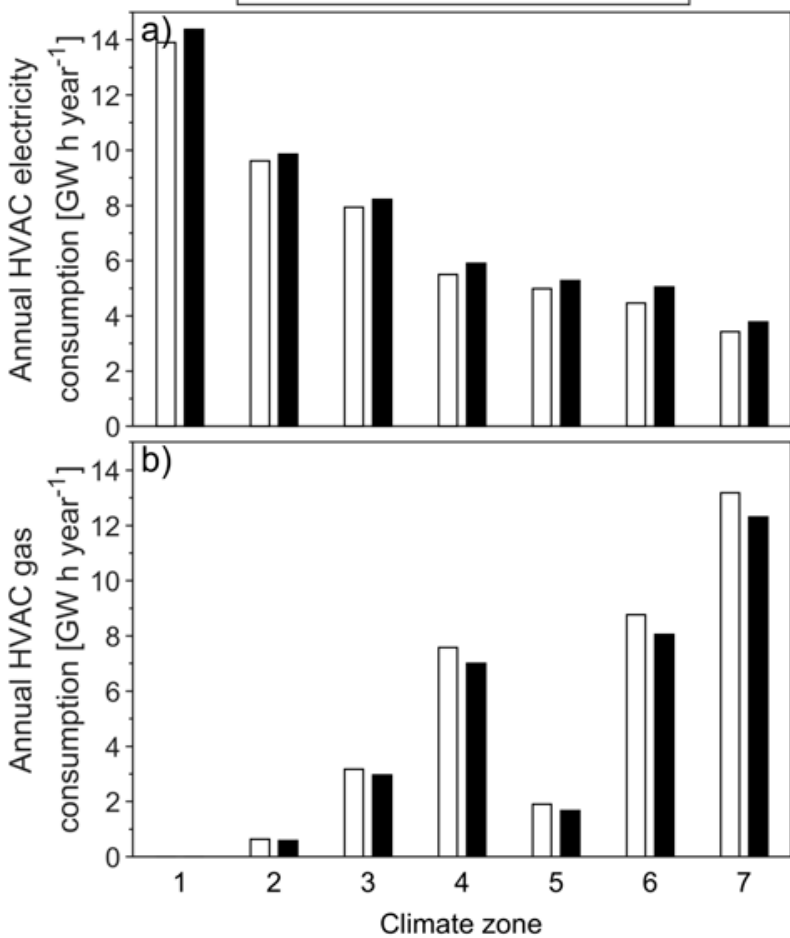

Figure 7: Annual HVAC a) electricity and b) gas consumption, calculated with and without use of the above-roof temperature model. Results are presented for the metal-coated roof with air-cooled condensers.

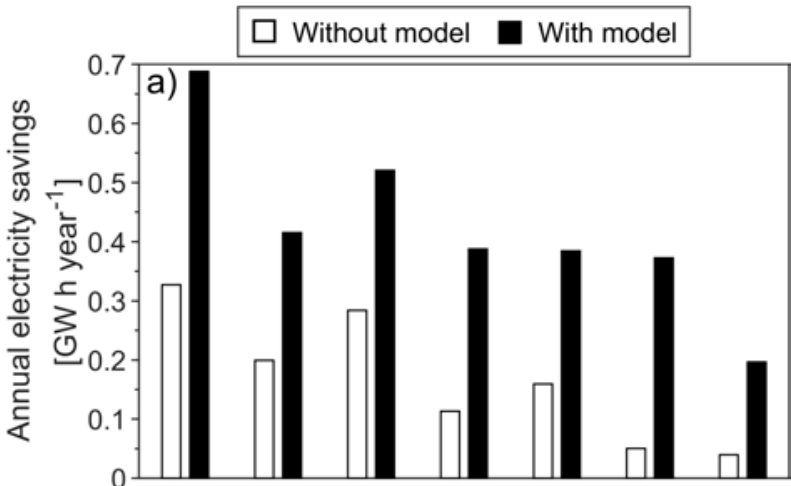

b)

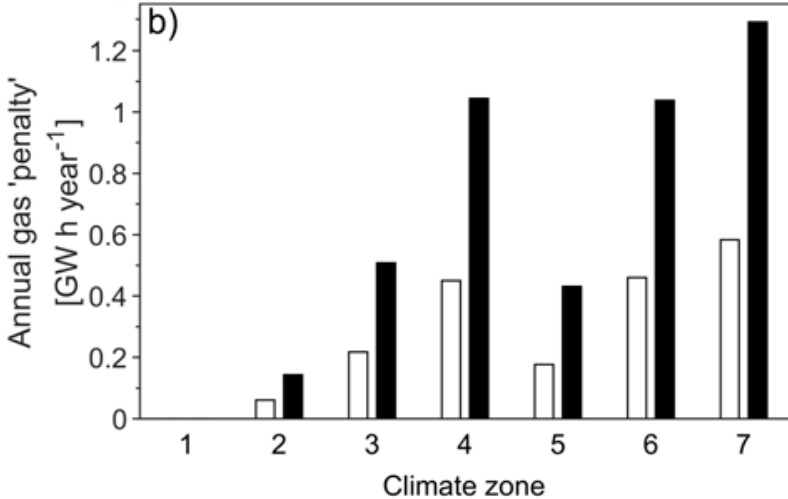

Figure 8: Annual a) electricity savings and b) gas 'penalty' (i.e. extra gas required to condition the building) caused by the installation of a cool roof instead of a metal-coated roof, calculated with and without use of the above-roof temperature model. Results are presented for air-cooled condensers.
These results demonstrate the importance of near-roof air temperature fields in the performance of cool roofs on large-footprint buildings with rooftop HVAC equipment. If near-roof air temperatures had been ignored (following what are currently conventional BPS practices), the effects of cool roofs would have been underestimated by more than $50 \%$ in most cases included in this study. Despite the relatively small magnitude of total electricity savings and gas penalties that were predicted (in the range 4-26\%), underestimation of such effects by a factor of two or more could significantly alter the outcomes of many real-world BPS investigations, e.g. cost-benefit analyses of cool roof technologies for particular building projects.

It should be recognised that the building model used in the present study was relatively simple in comparison to many real shopping centres, and that the use of a single model could never accurately represent the diverse set of existing shopping centres. However, the results presented here do provide useful insight into the magnitude of effect that above-roof air temperature fields are likely to have on such buildings.

\section{Conclusion}

The empirical model developed herein allows BPS practitioners to accurately account for local variations in outdoor air temperature that can affect rooftop HVAC equipment on large-footprint buildings. Only four input variables are required by the model, all of which are typically available in BPS: i) the mean roof surface temperature, ii) ambient air temperature, iii) reference wind speed, and iv) characteristic length of the roof surface (set here as the square-root of the roof area). Despite the relative simplicity of the model, predicted near-roof air temperatures matched experimentally measured values in the present study with a RMS error of $0.52 \mathrm{~K}$.

The effect of near-roof temperature anomalies on annual HVAC electricity and gas consumption was significant but not large (2.5-13.2\%) in the cases investigated here. However, the performance of technologies that influence roof surface temperatures, such as cool roofs, can be largely dependent on such effects. In the case of the shopping-centre building simulated here, with rooftop HVAC equipment and the minimum amount of roof insulation allowed for new buildings in Australia, approximately half $(44-85 \%, 61 \%$ on average) of the benefits and 'penalties' attributable to cool roofs would have been neglected if above-roof temperatures had not been modelled accurately. This could have significant implications on the results of cost benefit analyses for such roof coatings.

The above-roof temperature model was developed based on data from only three buildings, with roof areas in the range 16,000-76,000 $\mathrm{m}^{2}$. Therefore, further comparison of the model with experimental data would be a valuable exercise, and care should be taken if the model is applied to buildings that are significantly different than those studied already. 


\section{Acknowledgments}

This research is funded by the CRC for Low Carbon Living Ltd supported by the Cooperative Research Centres program, an Australian Government initiative. The authors would also like to acknowledge the contributions of BlueScope and Stockland, especially the contributions of Mark Eckermann, Jamie Adams, and Greg Johnson.

\section{References}

ASHRAE (2010) 'Performance Rating Method Reference Manual'. Americal Society of Heating, Refrigeration and Air-Conditioning Engineers.

ASTM (2015) 'ASTM C 1371: Standard Test Method for Determination of Emittance of Materials Near Room Temperature Using Portable Emissometers'. West Conshohocken, PA: American Society for Testing and Materials.

ASTM (2016) 'ASTM E 1918: Standard test method for measuring solar reflectance of horizontal and lowsloped surfaces in the field'. West Conshohocken, PA: American Society for Testing and Materials.

Australian Building Codes Board (2016) 'National Construction Code'. Available at: http://www.abcb.gov.au.

Carter, G. (2011) 'Issues and solutions to more realistically simulate conventional and cool roofs', in Proceedings of Building Simulation 2011: 12th Conference of international building performance simulation association (IBPSA). Sydney, 14-16 November 2011.

Carter, G. and Kosasih, B. (2015) 'Not so cool roofs', in AIRAH's Future of HVAC 2015 Conference. Melbourne, Australia.

Clear, R. D., Gartland, L. and Winkelmann, F. C. (2003) 'An empirical correlation for the outside convective air-film coefficient for horizontal roofs', Energy and Buildings, 35(8), pp. 797-811.

Costanzo, V., Evola, G., Marletta, L. and Gagliano, A. (2014) 'Proper evaluation of the external convective heat transfer for the thermal analysis of cool roofs', Energy and Buildings, 77, pp. 467-477.

EnergyPlus (2010) 'EnergyPlus Engineering Reference: The Reference to EnergyPlus Calculations.' US Department of Energy.

EnergyPlus $^{\mathrm{TM}}$ (2006) RMY Australia Representative Meteorological Year Climate Files.

EPA (2014) Reducing Urban Heat Islands: Compendium of Strategies - Cool Roofs. Available at: https://www.epa.gov/sites/production/files/201408/documents/coolroofscompendium_ch4.pdf.

Mirsadeghi, M., Costola, D., Blocken, B. and Hensen, J. L. M. (2013) 'Review of external convective heat transfer coefficient models in building energy simulation programs: Implementation and uncertainty', Applied Thermal Engineering, 56(1), pp. 134-151.

Monin, A. S. and Obukhov, A. M. F. (1954) 'Basic laws of turbulent mixing in the surface layer of the atmosphere', Contrib. Geophys. Inst. Acad. Sci. USSR, 151(163), p. e187.

NREL (2015) 'EnergyPlus Documentation: Application Guide for EMS Energy Management System User Guide’, pp. 1996-2015.

Pisello, A. L. (2017) 'State of the art on the development of cool coatings for buildings and cities', Solar Energy, 144, pp. 660-680.

Pisello, A. L., Santamouris, M. and Cotana, F. (2013) 'Active cool roof effect: impact of cool roofs on cooling system efficiency', Advances in building energy research, 7(2), pp. 209-221.

Richards, P. J. and Norris, S. E. (2011) 'Appropriate boundary conditions for computational wind engineering models revisited', Journal of Wind Engineering and Industrial Aerodynamics, 99(4), pp. 257-266.

Santamouris, M., Synnefa, A. and Karlessi, T. (2011) 'Using advanced cool materials in the urban built environment to mitigate heat islands and improve thermal comfort conditions', Solar Energy, 85(12), pp. 3085-3102.

Wray, C. and Akbari, H. (2008) 'The effects of roof reflectance on air temperatures surrounding a rooftop condensing unit', Energy and Buildings, 40(1), pp. $11-28$.

Zhang, Y. (2011) 'An EnergyPlus simulation manager for parametrics’, jEPlus. 